\title{
Detection Backscatter Value of Mangrove Crab (Scylla Sp.) Using Cruzpro Fishfinder Pcff-80 Hydroacoustic Instrument
}

Lubis $\mathrm{MZ}^{*}$ and Pujiyati S

Department of Marine Science and Technology, Faculty of Fisheries and Marine Sciences, Bogor Agricultural University, Kampus IPB Dramaga, Indonesia

\begin{abstract}
Hydroacoustic method has been used in various field of marine research. Use hydroacoustic method is a method developed to obtain information about the mangrove crab (Scylla sp.). This study analyses the value Target Strength (TS), Power Spectral Density (PSD), and Fast Fourier Transform (FFT) used the instrument hidroakustik. Data collection was performed at the Laboratory of Marine Acoustics using instruments CruzPro PCFF-80 operated with a frequency of $200 \mathrm{kHz}$. Results of detection of the target by looking at the value of Target strength, strongest TS value can be seen at a depth of 0.6 meters from the transducer with estimations it is the result of target detection. The target strength (TS) of the mangrove crab (Scylla sp.) ranged between -50 and $-54 \mathrm{~dB}$. TS value at ping number of $0-500$ have a greater value is the value of $-55 \mathrm{~dB}$, TS value at that time have in common with TS value at ping number 2500-3000. SV value is no different than the value of TS is caused using 1 target. Echo level (EL) value versus time has highest peak in the range of $115 \mathrm{~dB}$ with the lapse ping number is $15-25$, with values that are at the end of the echo of ping number of 70 with value is $132 \mathrm{~dB}$ rated Power Spectral Density (PSD) is actually located at $2900 \mathrm{~s}$, and depth of a pool is not affect the value of backscatter targets.
\end{abstract}

Keywords: Mangrove crab; Cruzpro; Fast fourier transform (FFT); Target strength (TS); Power spectral density (PSD)

\section{Introduction}

Hydroacoustic instruments have been an indispensable tool to study the ocean. Echo sounder is one of the acoustic instruments used to remotely classify distributions of biological organisms such as fish and plankton [1], and Cruzpro instrument, substrate category using hydroacoustic have been done [2,3]. Research on the Power Spectral Density (PSD) of mammals has been done [4,5]. Mangrove crabs are one type of commodity that potential to be cultivated and consumed because it has a high economic value, especially crabs mature gonads or is laying eggs, adults and obese [6]. The existence of this species has been widely cultivated in ponds, and crab seeds taken from nature, as has been done cultivators in Karawang, West Java. Broadly speaking, mud crab farming system which has been recognized by dmasyarakat is an enlargement of the seed becomes crab size of consumption, fattening, production of soft shell crabs and crab spawn production. Mangrove crabs caught from the waters of estuaries and channels ponds. Mud crabs prefer to live in relatively shallow waters with muddy grounds. Areas suitable for the location of crab cultivation is essentially a muddy pond with a temperature of $25-35^{\circ} \mathrm{C}, \mathrm{pH} 7.0-9.0$, DO more than $5 \mathrm{ppm}$, and salinity ranges from $10-30 \mathrm{ppt}$ [7].

Mangrove crab known as carrion eating everything (omnivorousscavenger). Mangrove crabs generally prey on gastropods, bivalves and a variety of small animals they can catch, but they are also scavengers enterprising (vigorous scavenger) [8]. As scavengers they are easily caught by baited traps in both the commercial and recreational arrest [9]. Mangrove crabs are voracious scavengers (scavenger voracious), which can search for and prey carcasses in the murky waters and estuarine mangrove forest [10]. Figure of mangrove Crabs (Scylla sp.), will be showed in (Figure 1).

Hydroacoustic technology utilizes underwater search with a strong voice to detect, observe and calculate the physical and biological parameters. Hidroakustik technology is a popular method used for many years in a survey of fishery resources. Research in the field hidroakustik continues to experience significant growth. Based on the theory and formula hidroakustik, this technique is now being adopted to survey coral reefs. Their growing need to classify and map the marine ecosystems at various spatial scales in favour of science-based ecosystem for marine management [11,12] (Figures 2 and 3).

The transducer is used for recording data can be placed on an order that has been modified to avoid the influence of waves. This research will use an acoustic frequency. The results obtained with the acoustic method can be combined with the visual observation by taking a photo or image. Studies evaluating the mud crabs using hidroakustik still not been done. Therefore, the research to be able to analyze the existence of mangrove crabs acoustically by using the acoustic method of a single beam echosounder. This study provides quantitative information about the value of backscatter from mangrove crabs. Mangrove crab is also a valuable economic and highly prevalent Area-rich coastal mangrove forests.
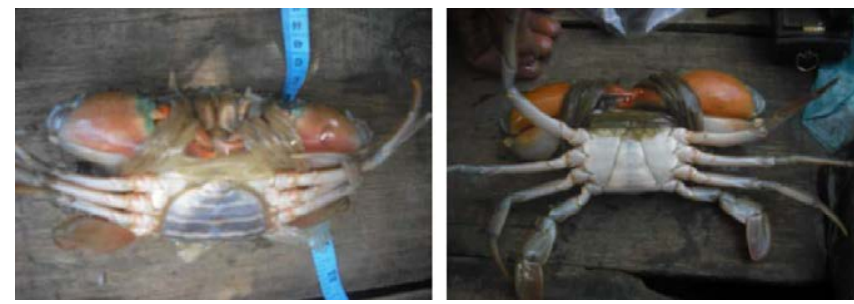

a) Female mangrove crabs b) Male mangrove crabs

Figure 1: Personal documentation of mangrove crabs.

*Corresponding author: Muhammad Zainuddin Lubis, Department of Marine Science and Technology, Faculty of Fisheries and Marine Sciences, Bogor Agricultural University, Jln. Agatis, Kampus IPB Dramaga, Bogor 16680, Indonesia Tel: 08811781329; E-mail: lubiszainuddin@gmail.com, muhammadz0921@apps.ipb.ac.id

Received April 25, 2016; Accepted May 02, 2016; Published May 12, 2016

Citation: Lubis MZ, Pujiyati S (2016) Detection Backscatter Value of Mangrove Crab (Scylla Sp.) Using Cruzpro Fishfinder Pcff-80 Hydroacoustic Instrument. J Biosens Bioelectron 7: 205. doi:10.4172/2155-6210.1000205

Copyright: ( $) 2016$ Lubis MZ, et al. This is an open-access article distributed under the terms of the Creative Commons Attribution License, which permits unrestricted use, distribution, and reproduction in any medium, provided the original author and source are credited. 
Citation: Lubis MZ, Pujiyati S (2016) Detection Backscatter Value of Mangrove Crab (Scylla Sp.) Using Cruzpro Fishfinder Pcff-80 Hydroacoustic Instrument. J Biosens Bioelectron 7: 205. doi:10.4172/2155-6210.1000205

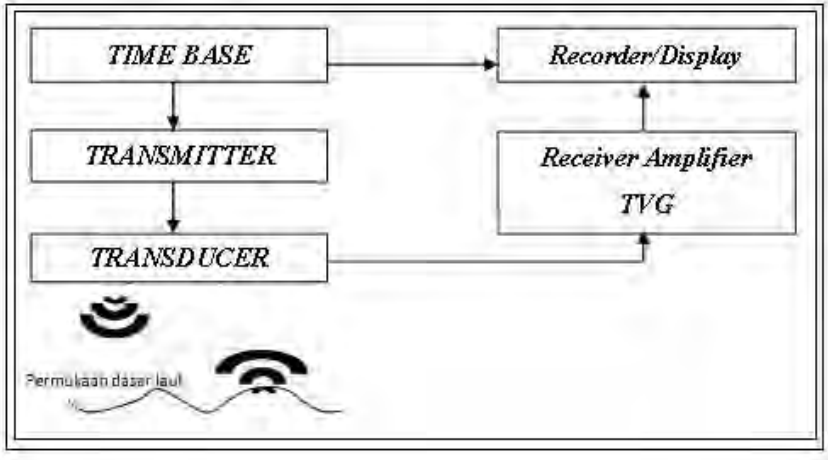

Figure 2: Main components and basic principles echosounder [12].

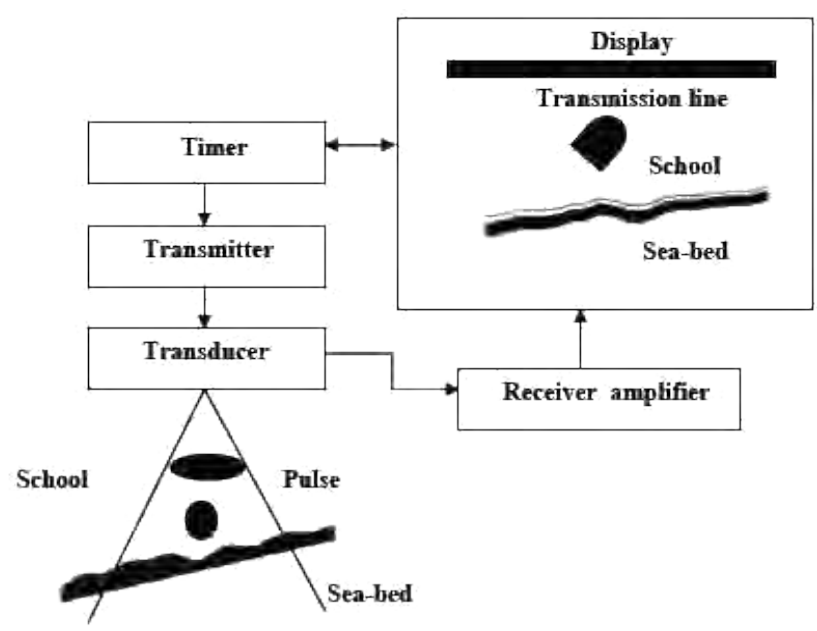

Figure 3: Working principle Single beam echosounder [13].

\section{Research Methods}

\section{Location}

This research was doing by Marine Acoustics Laboratory (MAL), Bogor Agricultural University, Department of Marine Science and Technology (Watertank) FPIK-IPB.

\section{Tools, materials and methods}

Tools and materials used in research methods can be seen in Tables 1 and 2 , and the instrument.

Collecting data in this research carried out in two ways, namely by visual observation (direct observation) and using the acoustic method performed on an investigation. Watertank experimental in research can be seen in (Figure 4).

Tools used for recording acoustic data is a single beam echosounder CruzPro PcFF80 with the type of transducer THDT-5 Bronze Long Stem Thru Hull used as a means of sounding the seabed to identify each type of substrate reflection waters (coral and sand). Before performing an acoustic sounding process, first performed the process of setting tool (Table 3). Transmitter power used at the making of acoustic data is 320 watts. A process flow chart recording acoustic data using PcFF80 Cruzpro can be seen in (Figure 4) is a flow chart of data retrieval using Cruzpro, (Figure 5) will be showed about methodology flowchart of research (Figures 5 and 6).

\section{Volume backscattering strength (SV)}

In addition to the value of surface backscattering strength (SS), may also be generated volume backscattering strength value (SV) can be derived from the value of surface backscattering strength (SS). In the process of differentiating echo from some crabs and substrate is then performed by quantification of echo signals to produce a data based on the average value obtained. SV value of coral types in the extract from the first reflection (E1) which indicates the degree of roughness (roughness) and the reflection of the second (E2) which indicates the level of hardness (hardness). SV value is obtained by connecting

\begin{tabular}{|c|l|}
\hline No & \multicolumn{1}{|c|}{ Tools and materials } \\
\hline 1 & Echosunder (Single beam, scientific Echosounder (Cruzpro PcFF80) \\
\hline 2 & Computer/PC \\
\hline 3 & Tail of adult male mangrove crab (with wide of karapas $(90-100 \mathrm{~mm})$ \\
\hline 4 & Cabel roll \\
\hline 5 & Gauges and fishing line \\
\hline
\end{tabular}

Table 1: Tools and materials.

\begin{tabular}{|l|l|}
\hline Specifications & Detail of magnitude \\
\hline Transducer type & THDT-5 Long Stem Bronze Thru Hull Transducer \\
\hline Transducer frequency & Dual frequency, $50 \mathrm{kHz}$ and $200 \mathrm{kHz}$ \\
\hline Operating voltage & $\begin{array}{l}\text { 9.5 to } 16.0 \mathrm{VDC}, 0.05 \text { amps nominal, } 4.7 \text { amps peak at } \\
\text { max power }\end{array}$ \\
\hline Output power & $\begin{array}{l}2560 \text { watts peak-to-peak }(320 \mathrm{~W} \text { RMS }) \\
24 \mathrm{KW} \text { DSP processed power }(3200 \mathrm{~W} \text { RMS })\end{array}$ \\
\hline Depth & 1000 feet or more $(200 \mathrm{kHz}) 1500$ feet or more $(50 \mathrm{kHz})$ \\
\hline Temperature & 0 to $50^{\circ} \mathrm{C}\left(32\right.$ to $\left.122^{\circ} \mathrm{F}\right)$ \\
\hline Interface box & $\begin{array}{l}100 \times 80 \times 50 \mathrm{~mm}(4 \times 3.2 \times 2 \text { inch). Powder Coated } \\
\text { Aluminum Extrusion }\end{array}$ \\
\hline Interface & $\mathrm{RS}-232,115 \mathrm{KBaud}, \mathrm{serial} \mathrm{data} \mathrm{and} \mathrm{USB}$ \\
\hline Source level & $163 \mathrm{~dB}(200 \mathrm{kHz}), 156 \mathrm{~dB}(50 \mathrm{kHz})$ \\
\hline Receiving sensitivity & $-185 \mathrm{~dB}(200 \mathrm{kHz}),-173 \mathrm{~dB}(50 \mathrm{kHz})$ \\
\hline Beam width & $11^{\circ}(200 \mathrm{kHz}), 45^{\circ}(50 \mathrm{kHz})$ \\
\hline Transducer diameter & $6 \mathrm{~cm}$ \\
\hline
\end{tabular}

Table 2: Specifications of single beam echosounder CruzPro PcFF80.

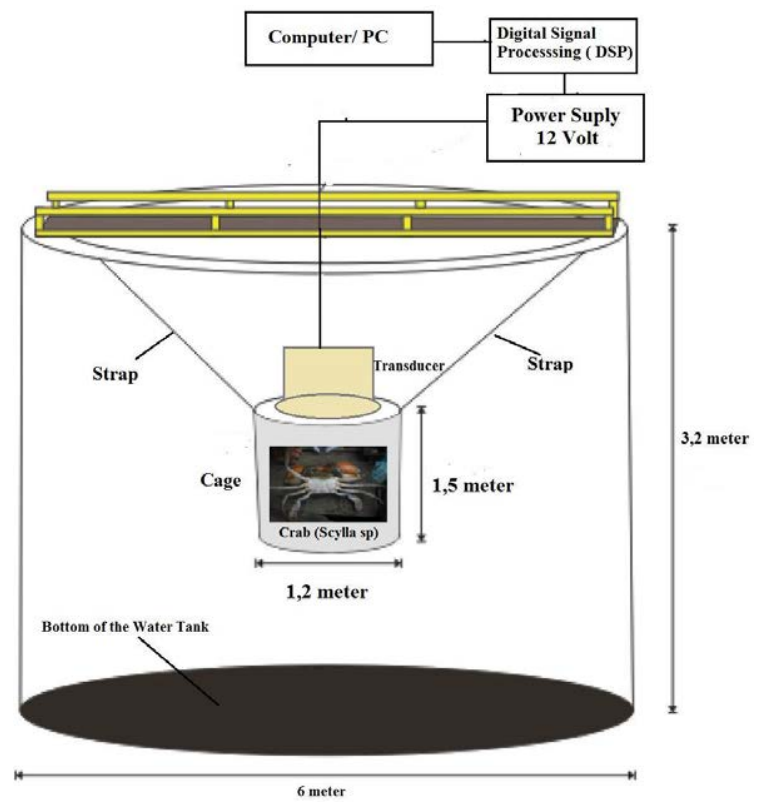

Figure 4: Water tank experimental. 
Citation: Lubis MZ, Pujiyati S (2016) Detection Backscatter Value of Mangrove Crab (Scylla Sp.) Using Cruzpro Fishfinder Pcff-80 Hydroacoustic Instrument. J Biosens Bioelectron 7: 205. doi:10.4172/2155-6210.1000205

\begin{tabular}{|c|c|}
\hline Parameter & Value \\
\hline Used Frequency & $200 \mathrm{kHz}$ \\
\hline Transmitter power $(\mathrm{W})$ & 320 \\
\hline Near field $(\mathrm{m})$ & 0.47 \\
\hline Sound Velocity $(\mathrm{m} / \mathrm{s})$ & 1516 \\
\hline Pulse duration $(\mathrm{ms})$ & 0.4 \\
\hline Ping rate $(\mathrm{s})$ & 0.334 \\
\hline Surface gain & 110 \\
\hline Change rate & 240 \\
\hline Amplifier gain $(\mathrm{dB})$ & -20.83 \\
\hline TS sphere $(\mathrm{dB})$ & -42.43 \\
\hline
\end{tabular}

Table 3: Methodology flowchart of research.

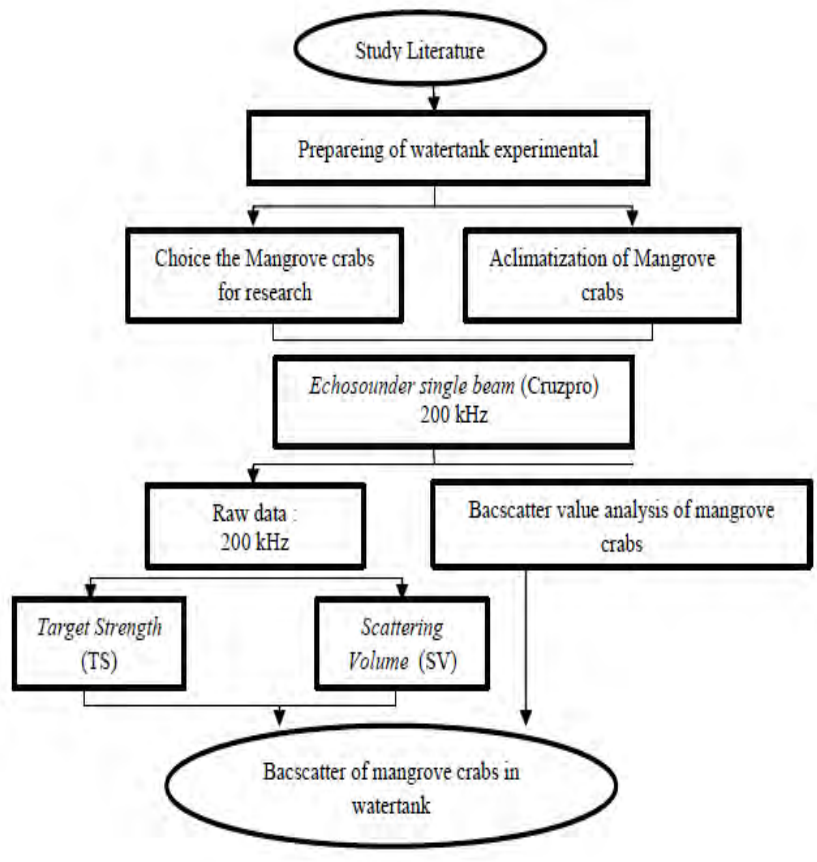

Figure 5: Methodology flowchart of research

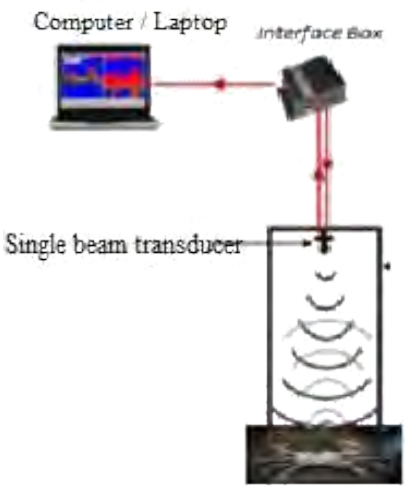

Figure 6: Process flow chart recording acoustic data using Cruzpro PcFF80.

the surface backscattering coefficient value (SS) and bottom volume backscattering coefficient (SV). Target Strength (TS) is a measure of reflectivity of the target after being charged active voice and is a function of frequency, aspect and target type. It can be seen by the following equation:

$$
\mathrm{TS}=10 \log (\mathrm{Ir} / \mathrm{Ii})
$$

TS: Target strength,

Ir: intensity of the reflected sound.

Ii: The intensity of the noise coming.

\section{Power spectral density (PSD)}

The frequency of a wave is naturally determined by the frequency source. The pace of the wave through a medium is determined by the properties of the medium. Once the frequency ( $\mathrm{f}$ ) and speed of sound (v) of the wave is already certain, then the wavelength (l) has been set. With the relationship $\mathrm{f}=1 / \mathrm{T}$ can be obtained equation (2).

$$
\lambda=\frac{v}{f}
$$

Because the study used the speed of sound in the liquid medium, i.e., sea water. Then the speed of sound in air is symbolized by (v) can be changed with the speed of sound in water which is denoted by $(\mathrm{C})$, so that equation (3),

$$
\lambda=\frac{C}{f}
$$

Power Spectral Density (PSD) is defined as the amount of power per frequency interval, in the form of mate, tinkers:

$$
\operatorname{PSD}=\frac{|X n|^{2}}{f} \ldots \ldots \ldots \ldots \ldots \ldots \ldots . . . . . . .\left(\frac{(\text { Amplitudo })^{2}}{H z}\right)
$$

\section{Result and Discussion}

When recording the data, the transducer emits sound waves so that the displacement of energy on the environment. The energy emitted by the transducer into a medium may disappear along the sound propagation in the medium. The process of energy loss is dependent on the distance between the point of observation to the transducer. Near field is the distance from the transducer surface to a distance where there is a high fluctuation of the intensity or pressure [13]. Lurton, Urick, Pujiyati $[14,15,16]$ also explained that the near field (fresnel zone) is a zone of influence from different points of phase with one another when the transducer transmits sound. Image result of the relationship between time with the target value can be seen in (Figure 7).

Results are shown in Figure 7 is generated when the relationship between the value of TS with a maximum depth is 2.5 meters, and the average value of Target Strength (TS) is $-60 \mathrm{~dB}$. TS value at ping

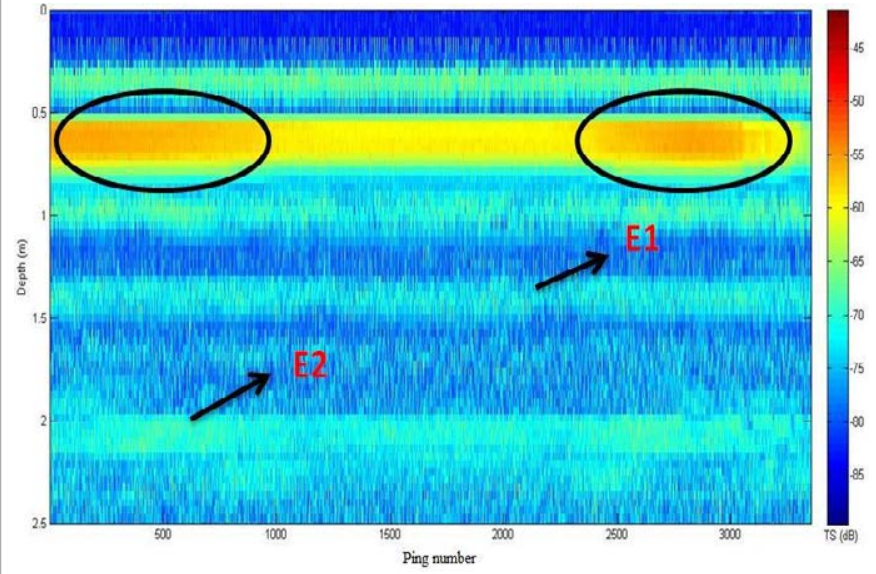

Figure 7: Relationship of time to the target strength (TS) 
number of $0-500$ have a greater value is the value of $-55 \mathrm{~dB}$, the value TS at that time have in common with TS value at ping number of 25003000. Results of detection of the target by looking at the value of TS can be seen the value of TS strongest at a depth of 0.6 meters from the transducer to estimate this is the result of the detection of targets detected by Cruzpro. Echo value level 1 (E1) can be shown at a depth of 1.5 meters with a value of $-70 \mathrm{~dB}$, while the value of $\mathrm{E} 2$ is located at a depth of 2 meters with a value equal to $-70 \mathrm{~dB}$, TS value of $\mathrm{E} 1$ indicated by the black line. Results time relationship with the depth can be seen in (Figure 8). The target strength of the mangrove crab ranged between -50 and $-54 \mathrm{~dB}$, this research have similar results to the study of the red crab in mexico [17].

In Figure 8 above were obtained relationship between Echo level versus time has the highest peak is at $115 \mathrm{~dB}$ with a time range that is on the interval $15-25 \mathrm{~s}$, with the final value echo that is currently on time $70 \mathrm{~s}$ with a value of $132 \mathrm{~dB}$. Echo level (EL) of target is $115 \mathrm{~dB}$ in time range 15-24 s, Echo Level (EL) of bottom is $132 \mathrm{~dB}$ with time $71 \mathrm{~s}$, this result of echo level have be same according in [18]. Results Fast Fourier Transform can be seen in Figure 9.
From Cruzpro used has a frequency of $200 \mathrm{KHz}$ while the results are displayed in Figure 10 shows the effects of changes between the frequency domain with the time domain will divide the frequency value is for 2, speed amplitude value in domain 1 is $0.5 \times 10^{6}$, and domain 2 is $8.2 \times 10^{6}$. In the sample frequency shown which has a 200 $\mathrm{KHz}$, although using tools with different specifications but the results and the methods used are similar to $[2,3,19]$. Results of Power Spectral Density (PSD) of mangrove crabs can be seen in Figure 10.

Figure 10 shows the highest spectral value at the time of the 2900 $s$ are shown in the image above is pink and the lowest value of the resulting PSD crab is in the range of 1000-2400 s time and time range of $3000-3500 \mathrm{~s}$. this proves that the peak frequency of the value of Power Spectral Density (PSD) actually is located at $2900 \mathrm{~s}$ [20], hydroacoustic result and behaviour the mangrove crabs in tank have similar according in $[21,22]$.

\section{Conclusion}

From this research has been done using echosounder (Single beam, scientific echosounder (Cruzpro PcFF80) showed no difference

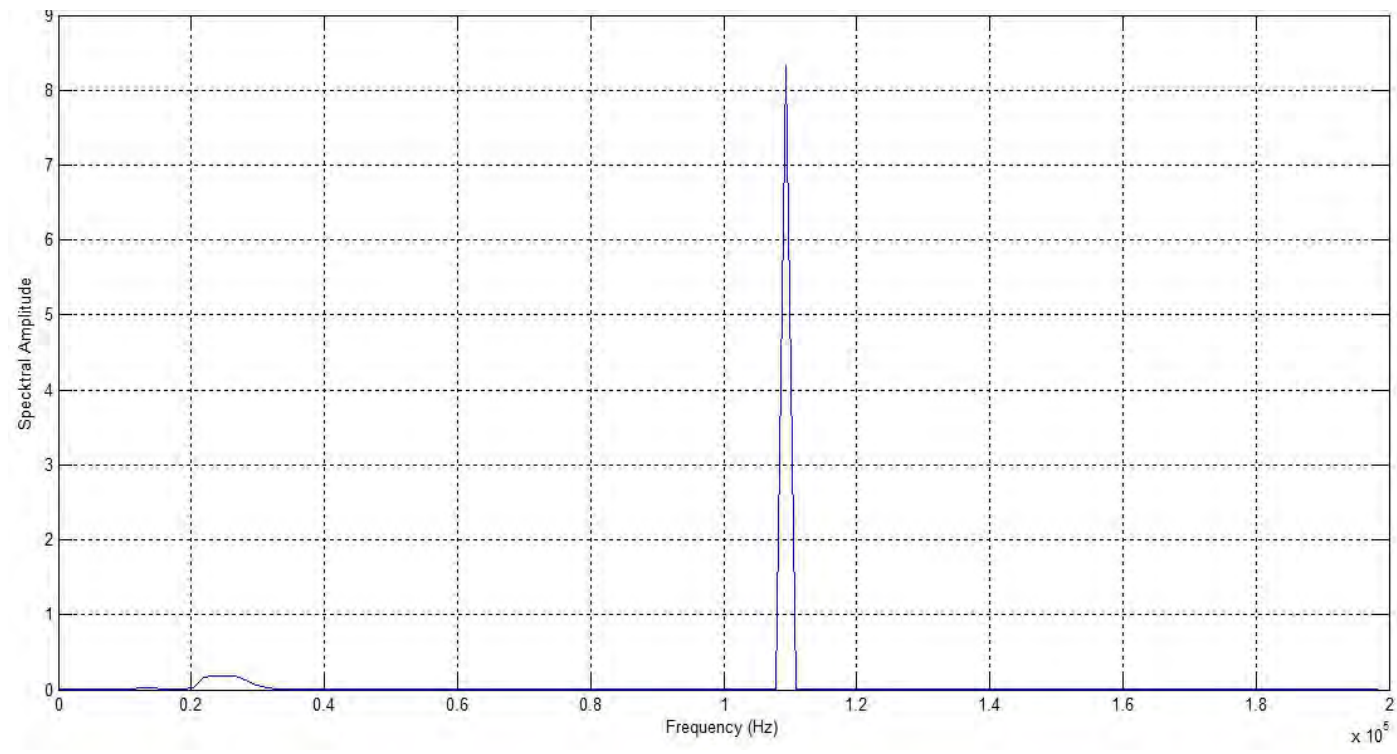

Figure 8: Time relationship with the depth.

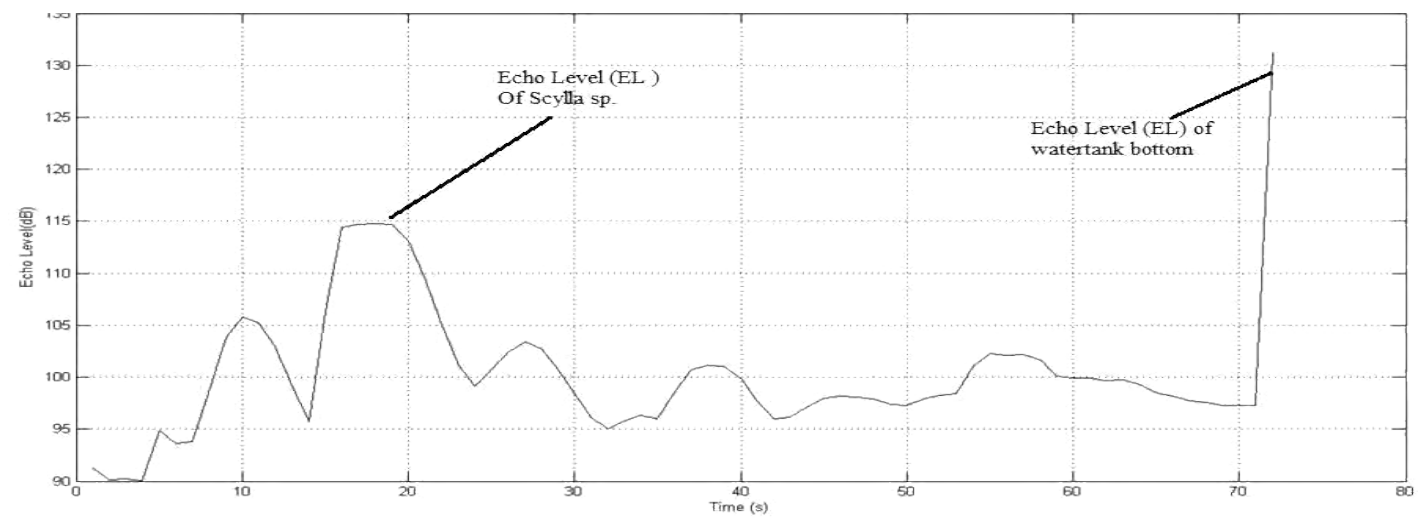

Figure 9: Fast Fourier Transform of mangrove crab. 
Citation: Lubis MZ, Pujiyati S (2016) Detection Backscatter Value of Mangrove Crab (Scylla Sp.) Using Cruzpro Fishfinder Pcff-80 Hydroacoustic Instrument. J Biosens Bioelectron 7: 205. doi:10.4172/2155-6210.1000205

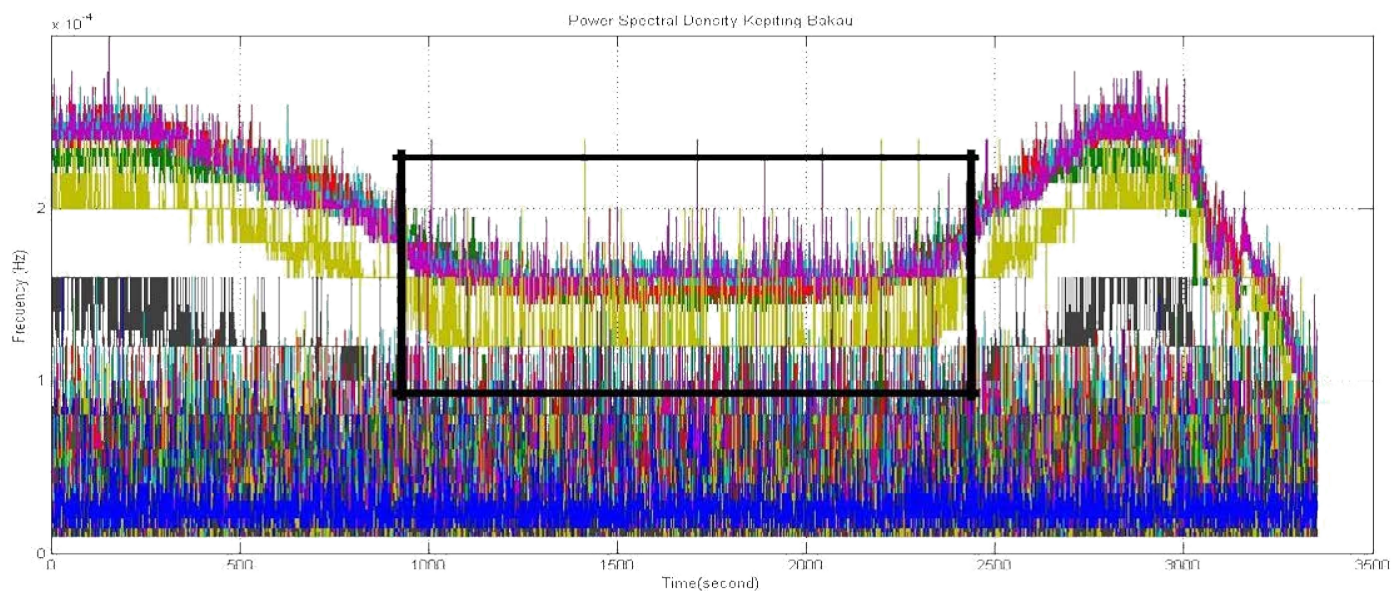

Figure 10: Detection PSD of mangrove crabs.

between the value of Target Strength (TS) with a value Scattering Volume (SV) using 1 target is mangrove crab, and the depth of a pool is not affect the value of backscatter targets.

\section{References}

1. MacLennan D, Simmonds EJ (1992) Fisheries Acoustics, Chapman \& Hall, London.

2. Manik HM (2013) Measuring acoustic backscattering strength of underwater target using high frequency sonar. In Instrumentation, Communications, Information Technology, and Biomedical Engineering (ICICl-BME), 3rd International Conference, Bandung pp: 381-384.

3. Pujiyati S (2008) Hidroakustik method approach to the analysis of the linkages between water bottom substrate type with demersal fish communities.

4. Wulandari PD, Pujiyati S, Hestirianoto T, Lubis MZ (2016) Bioacoustic characteristic click sound and behaviour of male dolphins bottle nose (Tursiops aduncus). J Fisheries Livest Prod 4: 160.

5. Lubis MZ (2014) Bioacoustics Stridulatory Motion guppy (Poecilia reticulata) Acclimatization Process When salt levels. Scientific Repository

6. Kanna I (2002) Mind power crab bakau, hatchery and enlargement. Kanisius, pp: 80.

7. [FAO] Food and Agriculture Organization (2011) The state of word fisheries and aquaculture. Rome (IT) : FAO

8. Hill BJ (1976) Natural food, foregut clearance-rate and activity of the crab Scylla serrata [abstrak]. Marine Biology 34: 109-116.

9. Hill F (2007) Annual status report: Queensland mud crab fishery 2007. Queensland Department of Primary Industries and Fisheries, Brisbane.

10. Mulya MB (2000) Abundance and Distribution of Mangrove crab (Scylla spp) And Keterkaiatannya With Biophysical Characteristics of Mangrove Forests in Karang Gading Wildlife And langkat Northeast North Sumatra Province. Bogor: Graduate, Institut Pertanian Bogor pp : 96.

11. Anderson JT, Holliday DV, Kloser R, Reid DG, Simard Y (2008) Acoustic seabed classification: current practice and future directions. ICES Journal of Marine Science 65: 1004-1011.

12. Johannesson KA, Mitson RB (1983) Fisheries acoustic a practical manual for acoustic biomass estimation. Roma: FAO Fisheries Technical Paper pp: 249.

13. Simmonds J, MacLennan DN (2005) Fisheries acoustics: theory and practice. (2nd edn.), Blackwell.
14. Lurton X (2002) An introduction to underwater acaoustic. Principles and applications. Praxis Publishing Ltd. Chichester, UK.

15. Urick RJ (1975) Principles of Underwater Sound. (4th edn.), Kingsport Press pp: 384.

16. Pujiyati S, Hartati S, Priyono W (2010) Effects Of grain size, roughness, and hardness of sea floor on back scattering value based on hydroacoustic detection. Journal of Tropical Marine Science and Technology 2: 59-67.

17. Gómez-Gutiérrez J, Domínguez-Hernández E, Robinson CJ, Arenas V (2000) Hydroacoustical evidence of autumn inshore residence of the pelagic red crab Pleuroncodes planipes at Punta Eugenia, Baja California, Mexico. Marine Ecology Progress Series 208: 283-291.

18. Thorne RE (1978) Investigations into the accuracy and precision of hydroacoustic techniques for fishery resource assessment. The Journal of the Acoustical Society of America 64: S96-S96.

19. Lee DJ (2002) Distribution characteristics of fish schools in the Yellow Sea and the East China Sea in the spring of 1997 . Journal of the Korean society of Fisheries Technology 38: 241-248.

20. Robinson CJ, Gomez-Aguirre S (2004) Tidal stream use by the red crab Pleuroncodes planipes in Bahia Magdalena, Mexico. Journal of experimental marine biology and ecology 308: 237-252.

21. George GJ, Brown KM, Peterson GW, Thompson BA (2008) Removal of black drum on Louisiana reefs to increase survival of eastern oysters Crassostrea virginica. North American Journal of Fisheries Management 28: 1802-1811.

22. Rothsehild, SJ, Ault JS, Goulletquer P, Jensen2t WP, Heral M, et al. (1991) Tbb oeclinb op cbesapeake bay oyster population: A Cbhtury Op Habitat Obstruction and Overfishing. 